\title{
Application of Big Data Complexity Analysis Hedging Operation of Derivative Financial Products
}

\author{
Cheng Chung Wu $\mathbb{D}^{1},{ }^{1}$ Menglin Yang $\mathbb{D}^{2},{ }^{2}$ Tiantong Yuan, ${ }^{3}$ Qionghui Fu, ${ }^{4}$ and Ya Ju Tsai ${ }^{5}$ \\ ${ }^{1}$ Department of Business College, Jiaxing University Nanhu College, Jiaxing, Zhejiang, China \\ ${ }^{2}$ Department of Cultural Creativity, ChangSha Commerce and Tourism College, ChangSha, Hunan, China \\ ${ }^{3}$ Department of Business Administration International College, Krirk University, Bangkok, Thailand \\ ${ }^{4}$ Department of Mathematics, Physics and Energy Engineering, Hunan Institute of Technology, Hengyang, Hunan, China \\ ${ }^{5}$ Department of Finance and Taxation, National Kaohsiung University of Science and Technology, Kaohsiung, Taiwan \\ Correspondence should be addressed to Menglin Yang; 23854509@qq.com
}

Received 20 November 2020; Revised 12 January 2021; Accepted 20 January 2021; Published 1 February 2021

Academic Editor: Wei Wang

Copyright (c) 2021 Cheng Chung Wu et al. This is an open access article distributed under the Creative Commons Attribution License, which permits unrestricted use, distribution, and reproduction in any medium, provided the original work is properly cited.

\begin{abstract}
This study is based on the situation of Taiwan listed companies as derivative financial products from 2015 to 2017, analyzing the relationship between the hedging of derivative financial products and characteristics of enterprises and the factors that affect the hedging decision-making of companies. It is found that even after the announcement of Taiwan's No. 34 and No. 36 bulletins, there are still some problems that are needed to improve in the disclosure of derivative financial product investment information by Taiwan's listed companies, at least in the disclosure of the reasons for this conduct which is still insufficient. In this study, twostage regression analysis method is applied to empirical analysis, and it is found that hedging activities are related to corporate characteristics, such as expected financial crisis costs, corporate size, equity issues, growth investment opportunities, and information asymmetry. In the investment of derivative financial products, enterprises should evaluate their own financial characteristics as a reference for the risk avoidance decision. At the same time, it is necessary to investigate different natures of hedging tools used in appropriate risk categories, so as to fully achieve the hedging effect and maximize the hedging benefits. This study also found that companies with higher growth investment opportunities, larger size, and higher financial crisis costs will tend to use derivative financial products for hedging. As for the impact of other industries, it is found that the electronic and electrical machinery industries are more active than other industries in hedging behaviors of undertaking derivative financial products' transaction.
\end{abstract}

\section{Introduction}

With the rapid development of economy, sound capital market development has become an important factor in economic development and in economic growth. It can not only regulate the supply and demand of funds in the economic society but also transfer idle funds to investors, accelerating the formation of capital and economic prosperity. However, the results of business operation begin to produce uncertain factors, so enterprises begin to have the motivation and demand to avoid risks. In order to respond to the strong demand for hedging of enterprises, the financial markets have developed many derivative financial products to serve as a channel for enterprises to avoid risks. Nevertheless, when new financial products continue to appear, they have far exceeded the speed of modification-relevant laws and regulations in various countries. As a result, the operation of derivative financial products by enterprises leads to huge losses, which also allow enterprises and the investing public to bear serious losses.

For example, the events of Orange County fund in California, Lehman Brothers, and the Bank of Bahrain in the U.K. all resulted from improper operation of derivative financial products and caused serious losses, which make people have doubts about the economic function of derivative financial products. Many enterprises still regard 
derivative financial products tend to keep away from them. On the contrary, the high degree of financial leverage and complexity of derivative financial products also make many enterprises dare not use them. In order to avoid making internal accounts to cover up large losses, Taiwan published the statement of Financial Accounting Standards No. 34 "accounting standards for financial products" and No. 36 "expression and disclosure of financial products" in 2006. After the formal implementation, the accounting standards for derivative financial products have a clear direction. The disclosure of the financial products undertaken by enterprises has gone from the external information to the internal information, making the transaction information more transparent.

However, after the implementation of bulletin No. 34 and bulletin No. 36, it does not seem to affect the use of derivative financial products by enterprises. Previous studies have found that most companies agree that the implementation of the bulletin will increase the cost of the company's financial statements. Meanwhile, the restrictions on the use of hedge accounting in the bulletin will lead to the fact that most companies choose to accept the profit or loss of derivative financial products, rather than spend time and cost to prepare relevant documents to adopt hedge accounting. Since August 2007, the financial crisis has emerged in the United States, from the earliest subprime mortgage crisis to the global financial storm caused by the Lehman Brothers event and Merrill Lynch Securities. This financial crisis had been out of control, resulting in losses of many listed companies in Taiwan undertaking derivative financial products during this period, and caused financial problems and bankruptcy of their companies. For example, in February 2008, Chunghwa Telecom lost nearly NT $\$ 4$ billion in operating options, and in April 2008, Dayi, a chip resistor factory, also reported that the loss of derivatives may exceed NT \$40 million. These cases further show the importance of an enterprise to financial risk management and undertaking derivative products.

Therefore, the use of derivative financial products as a hedge behavior must strengthen the internal control and audit system to ensure the safety and stable operation of investment institutions' assets. Some electronics industries or energy-based businesses in Taiwan can indeed reduce the exposure of enterprises to too much risks by making good use of the advantages of derivative financial products for hedging [1]. Therefore, what kind of factors determine the process of which derivative financial products are operated by enterprises constitutes an important and worth exploring question.

In the past, many scholars at home and abroad have researched the use of derivative financial products by enterprises. In foreign countries, due to the early disclosure of data, the relevant research is abundant. In the early stage, Mayers and Smith [2] and Smith and Stulz [3] examined the theoretical basis of the adoption of corporate risk aversion from the perspective of incomplete capital markets. Geczy et al. [4] integrated various hedging theories to test the decisive factors that affect the company's use of derivative financial products for hedging. Recently, there have been studies on the use of derivative financial products by companies, such as Mian [5], Joseph [6], and Nguyen and Faff [7], whose main research directions are "the reason of companies to avoid risks," "characteristics of companies," "the strategies for hedging of derivative financial products," and "the effect of companies' hedging."

On the domestic side, the previous two items are more common; the effect of corporate hedging is more about the financial industry, than the general industry. For example, Huang [8] used the general logistic regression to explore the motivations and behaviors of listed companies using derivative financial products to hedge their risks. Kuo [9] discussed the impact of corporate characteristics and financial soundness of listed companies in Taiwan on their operation derivative financial products. Tsai [10] analyzed the correlation between the hedging of derivative financial instruments and the characteristics of the companies, as well as the factors affecting the company's hedging decisions and the choice of hedging instruments. Secondly, in the past, scholars used traditional regression, logit analysis, or tobit analysis to study the determinants of using derivative financial products to hedge. For example, Mian [5] and Nguyen and Faff [7] used logit analysis to explore the determinants of general enterprises' use of derivative financial products to hedge, while tobit analysis was used by Tufano [11] and Haushalter [12] for researching. The logit analysis method can only know whether derivative financial products are used. This method mainly belongs to the category scale analysis, which may lead to biased results. The tobit analysis method can test the degree of the use of derivative financial products, which belongs to the proportional scale analysis. However, none of the above methods discuss the problem of sample selection bias in the data. In fact, the problem of sample selection bias often appears in regression models. It refers to the deviation caused by the limitations of the data or the researcher's personal behavior during sample extraction, resulting in the sample cannot fully represent the matrix of interest. For example, in the past, most of the related research studies on the use of derivative financial products' hedges by companies used listed companies as samples, which means unlisted companies were not included in the research sample. Therefore, the estimated research results are likely to be biased. The Heckman two-stage regression method used in this research can overcome this problem.

Therefore, the purpose of this study is to explore the determinants of the use of derivative financial products by Heckman's two-stage regression method. In the first stage, logit analysis is used to explore the variables that may affect the use of derivative financial products by companies and to test whether the listed companies as the research samples will generate sample bias. In the second stage, the least square method (ordinary least squares, OLS) is used to join inverse Mills ratio to explore the determinants of the adoption of different types of derivative financial products in the business community, so as to solve the problem of sample selection bias, and to explore the types of derivative financial products and operational strategies of enterprises after the implementation of No. 34 and No. 36 bulletins, so 
as to understand the hedging decisions of Taiwan enterprises in the application of derivative financial products.

\section{Review of the Literature}

The two-stage regression model proposed by Heckman [13] is used to estimate the possible sample selection bias based on the inverse Mills ratio. Heckman became the winner of the "Committed Bell Economics Award" in 2000, mainly analyzed the theory of sample selection, and developed methods to resolve sample selection bias. The so-called sample selection bias in econometrics is one of the research focuses of the limited dependent variable model. It refers to the bias caused by the limitations of the data or the researcher's personal behavior during sample extraction, resulting in the sample cannot fully represent the interested matrix [14]. The discussion of this subject mainly originates from labor economics. Taking labor economics as an example, if there is interest in women's educational return rate, theoretically, the matrix should be all women. However, the sample obtained by the researcher only includes women with work. Those women without work are not included in the sample because of lack of salary data. If we ignore this point in the research and directly use the existing samples to make regression analysis on salary and education, the estimated rate of return to education is likely to be biased. Or when studying the relationship between education degree and personal income, generally speaking, there will be deviation in the source of samples. For example, the data of people with high education are easy to get, while the data of people with low education are not easy to get, because their work may not be fixed or even often unemployed. If we only analyze the data collected, the impact of education on personal income will be underestimated.

Therefore, Heckman put forward the famous Heckman correction method in 1979. This method is divided into two steps: step one is that the researcher should establish a model firstly which can measure the work participation probability of individual workers according to the economic theory and then predict the work probability of each worker. The second step is for the researchers to combine the probability of these predicted workers into an additional explanatory variable (Mills lambda), together with education, age, and other variables to correct the sample selection problem, so that the estimated wage relationship is very appropriate in the statistical sense.

Since Heckman [13] proposed the two-stage regression model, in addition to being widely used by researchers in the field of economics, scholars in other fields have often applied two-stage regression models to solve the problem of sample selection bias. Shiue et al. [14] used Heckman's two-stage regression procedure to explore the impact of self-selection of accountants employed by the company on the pricing of audit fees; Lin et al. [15] used Heckman's two-stage regression to explore the sample selection error of the traditional financial crisis early-warning model. However, the relevant research on the use of derivative financial products by enterprises does not use the Heckman two-stage regression procedure to explore the problem of sample bias. In fact, because the financial information of listed companies is easy to obtain, in the past, almost all the relevant research studies on derivative financial products used listed companies as samples, and none of the unlisted companies were included in the research samples. If only the data of listed companies are collected for analysis, the results are likely to produce sample bias. Therefore, this study uses Heckman's two-stage regression to explore the determinants of the adoption of derivative financial products, so as to solve the problem of sample bias.

\section{Research Data and Design}

3.1. Research Model. In this study, the two-stage estimation method of Heckman [13] is used to explain the binary selection model. In the first stage, the logistic regression model is used first; in the second stage, the ordinal least squares (OLS) regression is used to test. The following is the explanation of the two models.

3.1.1. Logistic Regression Model. The model with the binary variable as the dependent variable has a nonlinear relationship between the independent variable and the event probability, while the linear probability model cannot fit the nonlinear relationship. Because the general least square model is not suitable, it is suggested to use nonlinear function to analyze the binary dependent variable.

The nonlinear relationship between the conditional probability $P\left(y_{i} 1 \mid x_{i}\right)$ and $x_{i}$ is usually a monotonic function, that is to say, monotonically increasing with $P\left(y_{i} 1 \mid x_{i}\right)$ or monotonically decreasing with $x_{i}$. One option is a curve with an S-shaped range between $(0,1)$. When $x_{i}$ approaches negative infinity, $E\left(y_{i}\right)$ approaches 0 , and when $x_{i}$ approaches positive infinity, $E\left(y_{i}\right)$ approaches 1 .

It is assumed that there is a theoretical continuous reaction variable $y_{i}^{*}$, which represents the possibility of an event, and its range is from negative infinity to positive infinity. When the value of the variable crosses a critical point $c$ (such as $c=0$ ), an event occurs. So, the following can be observed.

When $y_{i}^{*}>0, y_{i}=1$.

In other cases, $y_{i}=0$.

Here, $y_{i}$ is the observed response variable. $y_{i}=1$ indicates that the event occurred, and $y_{i}=0$ indicates that the event did not occur. If it is assumed that there is a linear relationship between the response variable $y_{i}^{*}$ and the independent variable $x_{i}$, that is,

$$
y_{i}^{*}=\alpha+\beta x_{i}+\varepsilon_{i}
$$

from formula (1), we can get

$$
\begin{aligned}
P\left(y_{i}=1 \mid x_{i}\right) & =P\left[\left(\alpha+\beta x_{i}+\varepsilon_{i}\right)\right]>0 \\
& =P\left[\varepsilon_{i}>\left(-\alpha-\beta x_{i}\right)\right] .
\end{aligned}
$$

Generally, it is assumed that the error terms in equation (3) have a logistic distribution or a standard normal distribution. In order to obtain a cumulative distribution function (CDF), the probability of a variable needs to be less 
than a specific value. Therefore, we must change the direction of the inequality sign in equation (3). Since the logistic and normal distributions are symmetrical, equation (3) can be rewritten as

$$
P\left(y_{i}=1 \mid x_{i}\right)=P\left[\varepsilon_{i} \leq\left(\alpha+\beta x_{i}\right)\right]=F\left(\alpha+\beta x_{i}\right),
$$

where $F$ is the cumulative distribution function of $\varepsilon_{i}$.

The form of the distribution function depends on the hypothetical distribution of $\varepsilon_{i}$ in equation (3).

If $\varepsilon_{i}$ is assumed to be a logistic distribution, a logistic regression model is obtained; if we assume that $\varepsilon_{i}$ is a standard normal distribution, we get the probit model. Because $y_{i}^{*}$ cannot be observed directly, its measurement can neither be determined by the logistic regression model nor by the probit model. In the probit model, the variance of the error term $\varepsilon_{i}$ is $\pi^{2} / 3 \approx 3.29$. The standard logistic distribution has an average of 0 and a variance of $\pi^{2} / 3 \approx 3.29$. Such a variance was chosen because it allows a simpler equation for the cumulative distribution function:

$$
P\left(y_{i}=1 \mid x_{i}\right)=P\left[\varepsilon_{i} \leq\left(\alpha+\beta x_{i}\right)\right]=\frac{1}{1+e^{-\varepsilon_{i}}} .
$$

This function is called logistic function, it has an S-shaped distribution, and the function graph is shown in Figure 1. If the function value of $\varepsilon_{i}$ is changed from the negative infinity to the positive infinity, the graph in Figure 1 is obtained. Noting that on the left side of this graph, as it approaches negative infinity, the logistic function has

$$
\begin{aligned}
P\left(y_{i}=1 \mid x_{i}\right) & =\frac{1}{1+e^{-(-x)}} \\
& =\frac{1}{1+e^{\infty}} \\
& =0 .
\end{aligned}
$$

When $\varepsilon_{i}$ is approaching positive infinity, the logistic function has

$$
\begin{aligned}
P\left(y_{i}=1 \mid x_{i}\right) & =\frac{1}{1+e^{-(x)}} \\
& =\frac{1}{1+e^{-x}} \\
& =1 .
\end{aligned}
$$

As the graph shows, the logistic function $P\left(y_{i}=1 \mid x_{i}\right)=$ $\left(1 / 1+e^{-\varepsilon_{i}}\right)$ ranges from 0 to 1 , regardless of the value of $\varepsilon_{i}$. This property of the logistic function guarantees that the probability estimated by the logistic model will never be greater than 1 or less than 0 .

In order to obtain a logistic regression model based on the logistic function, the equation is rewritten as

$$
P\left(y_{i}=1 \mid x_{i}\right)=\frac{1}{1+e^{-\left(\alpha+\beta x_{i}\right)}} .
$$

In fact, this is the cumulative distribution function when $\varepsilon_{i}$ is $\left(\alpha+\beta x_{i}\right)$. Here, $\varepsilon_{i}$ is defined as a series of linear

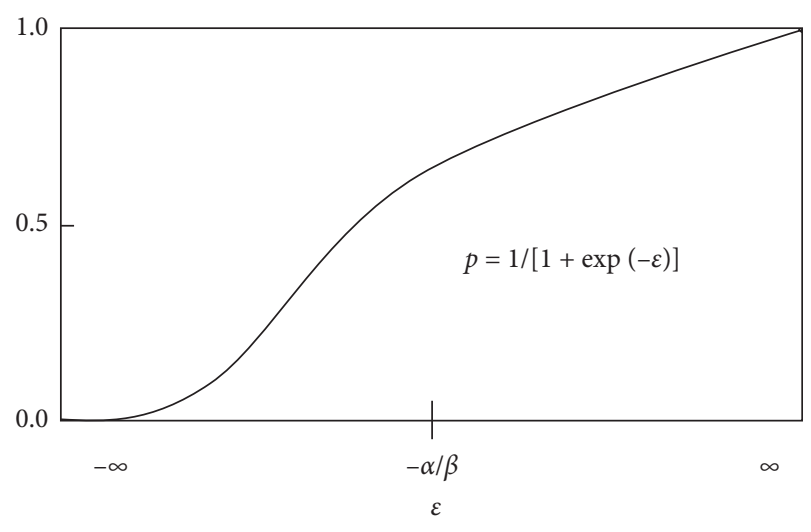

Figure 1: Graph of the logistic function.

functions that affect the probability of an event occurring, that is,

$$
\varepsilon_{i}=\alpha+\beta x_{i},
$$

$x_{i}$ is the independent variable, and $\alpha$ and $\beta$ are the regression intercept and regression coefficient, respectively.

For the sake of simplicity, here we take unary regression as an example. However, the same principle applies to multiple regression. By setting the marking principle of the conditional probability of event occurrence to $P\left(y_{i}=1 \mid x_{i}\right)=p_{i}$, the following logistic regression model can be obtained:

$$
\begin{aligned}
P_{i} & =\frac{1}{1+e^{-\left(\alpha+\beta x_{i}\right)}} \\
& =\frac{e^{\alpha+\beta x_{i}}}{1+e^{\alpha+\beta x_{i}}} .
\end{aligned}
$$

Among them, $p_{i}$ is the probability of an event occurring in the " $i$ " th" case, which is a nonlinear function composed of a variable $x_{i}$. However, this nonlinear function can be converted into a linear function.

First, define the conditional probability that no event will occur:

$$
\begin{aligned}
1-p_{i} & =1+\left[\frac{e^{\alpha+\beta x_{i}}}{1+e^{\alpha+\beta x_{i}}}\right] \\
& =\frac{1}{1+e^{\alpha+\beta x_{i}}} .
\end{aligned}
$$

Thus, the ratio of the probability of an event to the probability of an event not occurring is

$$
\frac{p_{i}}{1-p_{i}}=e^{\left(\alpha+\beta x_{i}\right)} \text {. }
$$

This ratio is called the odds of experiencing an event or simply odds. Odds must be positive because $0<p_{i}<1$ and there is no upper bound. Taking the natural logarithm of odds gives a linear function:

$$
\ln \left[\frac{p_{i}}{1-p_{i}}\right]=\alpha+\beta x_{i} .
$$


Equation (12) makes a natural logarithmic transformation of the logistic function, which is called the logit form, also known as the logit of $y$, which is $\operatorname{logit}(y)$. The importance of this transformation lies in that $\operatorname{logit}(y)$ has many properties of the available linear regression model. Logit $(y)$ is linear to its parameters and is related to the value of $x$, which ranges from negative infinity to positive infinity. As can be seen from equation (12) that when odds decreases from 1 to $0, \operatorname{logit}(y)$ is negative, and the absolute value is increasing. The coefficients' sum $\alpha$ and $\beta$ of the logit model can be explained as general regression coefficients. If the function of a variable is to increase the log odds, it means to increase the probability of an event. In terms of concept, equation (9) represents the logistic regression because it is a logistic publishing function, while equation (12) represents a logit model due to the logit form it used.

\subsubsection{Ordinal Least Squares Regression Analysis.}

Generally, when designing the hedging regression model of derivative financial products for listed companies that only estimate the sample of the listed company, the nonlisted companies are ignored. Therefore, in the case where such data observations are truncated, if they are directly evaluated by the least squares (OLS) estimation model or logistic regression model, sample selection bias will occur due to ignoring the samples of nonlisted companies. Therefore, this study uses Heckman's [13] two-stage estimation method to correct the bias caused by sample selection bias. In other words, it is to observe whether the regression coefficient estimated value of logistic regression model $\lambda$ Mills in the first stage is significant, to verify whether there is a sample selection error, and to make adjustments and analysis in the second stage.

According to Heckman's [13] two-stage estimation theory, the so-called $\lambda$ (inverse Mills ratio) is a variable to adjust the sample selection bias, so as to correct the bias generated in sample selection. This study uses the Heckman [13] measurement method to determine the robustness of the analysis results, that is, to find the correction term, inverse Mills ratio, in the first stage to replace the possible factors that may impact the company's operation risk aversion. In the second stage, the least square method (OLS) was used to estimate the model, and the inverse Mills ratio was incorporated into the regression model as a control variable. In the second stage of OLS regression, the types of derivative financial products are used as dependent variables, and 11 significant variables selected from the first stage of the logistic regression model are used as independent variables to explore the impact of corporate nature and financial variables on the adoption of derivative financial products.

3.2. Data Source and Sample Selection Standard. In this sample, the quarterly and monthly financial statements of listed companies in Taiwan from 2015 to 2017 are provided by the public information observatory to observe whether they are engaged in the operation of hedging goods. According to the research of Ko et al. [1], the following six levels are used to analyze the 13 variables that may affect the adoption of derivative financial products by enterprises, and collect the historical data of 13 variables of listed companies in the database of Taiwan economic news (TEJ) for Heckman two-stage application analysis. Table 1 shows the description of variable arrangement.

3.2.1. Financial Crisis Cost Level. The "liability ratio" is one of the important indicators of a company's financial risk. The total capital source of enterprise operation is divided into two parts, namely, foreign capital (liabilities) and self-owned assets (net value). Therefore, the total capital should be based on self-owned assets. The lower the ratio is, the more selfowned capital of an enterprise hands, the more flexible it is to pay for the temporary expenses, and the higher the debt ratio may erode the company's profits or even make the company's turnover sluggish.

Corporate risk or financial risk will increase the company's expected financial difficulties and bankruptcy costs. This study uses the "long-term debt ratio," which is the longterm debt divided by total assets, as the company's ability to repay long-term debt.

The "cash flow ratio" measures the amount of cash flow generated by the business activities in the current year, which is enough to pay multiple of current liabilities. The higher ratio is the better ratio. This ratio and the flow ratio are both indicators to measure the short-term flow of an enterprise. Generally, if the ratio of the enterprise decreases year by year, it means that the company's profitability may gradually decline.

3.2.2. Tax Burden Inspection Level. Interest cover not only reflects the profitability of an enterprise but also reflects the degree to which the profitability guarantees the repayment of matured debts. It is not only the premise basis for the enterprise to borrow money but also an important sign to measure the long-term solvency of an enterprise. To maintain normal solvency, the interest coverage ratio should be at least greater than 1 , and the higher the ratio, the stronger the company's long-term solvency. If the interest protection multiple is too low, the enterprise will face the risk of loss and reduced security and stability of debt service.

3.2.3. Enterprise Scale. In this study, "earnings per share," i.e., after-tax net profit divided by the number of common shares outstanding, represents the profitability of each share of the company. Therefore, it is often used to assess the profitability of the company and the risk of stock capital. The higher the ratio is, the better the company's operation is and the less likely it is to have a financial crisis. And the larger the ratio of fixed assets to total assets, the larger the scale.

3.2.4. Rights Issue Level. The impact of the shareholding ratio of directors, supervisors, and managers on shareholders' equity. 
TABLE 1: Research variables.

\begin{tabular}{|c|c|c|}
\hline Measurement level & Variable name & Formula \\
\hline $\begin{array}{l}\text { Expected financial crisis } \\
\text { costs }\end{array}$ & $\begin{array}{l}\text { Debt ratio } \\
\text { Long-term debt ratio } \\
\text { Cash flow ratio }\end{array}$ & $\begin{array}{c}\text { Debt ratio }(\text { TLR })=\text { total debt } / \text { company market value } \\
\text { Long-term debt ratio }(\text { LLR })=\text { long-term debt } / \text { total assets } \\
\text { Cash flow ratio }(\mathrm{CFR})=\text { cash flow from operating activities } / \text { current } \\
\text { liabilities }\end{array}$ \\
\hline Tax benefits and hedging & Interest coverage ratio & $\begin{array}{c}\text { Interest protection multiple }(\mathrm{TIE})=\text { net profit before interest } / \text { interest } \\
\text { expense }\end{array}$ \\
\hline $\begin{array}{l}\text { Enterprise size and } \\
\text { hedging }\end{array}$ & $\begin{array}{l}\text { Earnings per share } \\
\text { Fixed asset ratio }\end{array}$ & $\begin{array}{c}\text { Earnings per share }(\text { EPS })=\text { net after-tax common shares outstanding } \\
\text { Fixed asset ratio }(\text { FAR })=\text { fixed assets / total assets }\end{array}$ \\
\hline Equity issues & $\begin{array}{l}\text { Shareholding ratio of directors } \\
\text { and supervisors } \\
\text { Executive shareholding ratio }\end{array}$ & $\begin{array}{c}\text { Shareholding ratio of directors and supervisors }(\mathrm{DHR})=\text { total } \\
\text { shareholdings of directors and supervisors } \\
\text { Executive shareholding ratio }(\mathrm{CHR})=\text { bottom total shares held by senior } \\
\text { management }\end{array}$ \\
\hline $\begin{array}{l}\text { Growth investment } \\
\text { opportunities }\end{array}$ & $\begin{array}{l}\text { Operating gross margin } \\
\text { R\&D expense ratio } \\
\text { Operating income }\end{array}$ & $\begin{array}{c}\text { Operating gross margin (GPMS) }=\text { (net operating income - operating } \\
\text { costs) / net operating income } \\
\text { Research and development cost ratio }(\mathrm{RD})=\mathrm{R} \& \mathrm{D} \text { expenses / number of } \\
\text { common shares outstanding } \\
\text { Operating income (OR) }\end{array}$ \\
\hline Information asymmetry & Current ratio & $\begin{array}{c}\text { Current ratio }(\mathrm{CR})=\text { current assets / current liabilities } \\
\text { Quick ratio }(\mathrm{QR})=(\text { current assets }- \text { inventory }- \text { prepayment }) / \text { current } \\
\text { liabilities }\end{array}$ \\
\hline
\end{tabular}

3.2.5. Future Growth Opportunity Level. This study uses "operating gross margin" to measure the company's future investment opportunities. The "operating income" is used to measure the expected profitability. The "R\&D expense ratio" means that the larger the company's existing resource ratio, the higher the growth opportunity.

3.2.6. Information Asymmetry Level. "Liquidity ratio" refers to the assets that can be converted into cash within one year or one business cycle. When the company is in a hurry to pay off current liabilities, the most effective one is the assets with quick cash or liquidity, that is, current assets. Therefore, the higher the ratio, the better the company's response capacity and the better its short-term debt repayment performance, being able to repay short-term liabilities safely without worrying about turnover problems.

"Quick ratio" is to subtract the lower part of liquidity from the current assets. This ratio shows the company's short-term debt service situation better than the current ratio because the ratio of inventory to current assets of some companies is too high. Once the company really wants to repay its debts, it cannot quickly clear the inventory and obtain funds for a while. If the quick ratio is too low, the company has a very high wind in case of poor turnover.

3.3. Research Variable Measurement. According to the study of whether listed companies engaged in the operation of hedging products before the implementation of Taiwan No. 34 and No. 36 by Ko et al. [1], this study extracts 13 variables that may affect the adoption of derivative financial products by enterprises and defines the use of derivative financial products for hedging as 1 and the nonuse as 0 ; in addition, according to the industries of listed companies, they are divided into electronics and electrical appliances, including electronics, electrical machinery, and electrical and cable industries. The value of the operating type is 1 ; plastic textile industry is defined as 2 , including plastic industry, textile industry, chemical industry, rubber industry, glass industry, paper industry, and biotechnology industry; construction of iron and steel industry is defined as 3, including construction industry, cement industry, and steel industry; automobile transportation is defined as 4 , including automobile industry, transportation industry, tourism industry, and shipping industry; comprehensive is defined as 5, including food industry, trade department stores, and comprehensive enterprises; financial industry is defined as 6, including banking, insurance, financial control, and securities. There are four types of hedging commodities: forward foreign exchange contracts, exchange contracts, options, and futures. According to the above variable definitions, the operational definitions of each variable are summarized in Table 2.

3.4. Model Design. According to the above calculation, firstly, this study uses 13 independent variables to make the first-stage regression analysis on the impact of Taiwan listed companies' operation of hedging derivative financial products, substituting the variables into the following formula:

The first stage: logistic regression analysis:

$$
\begin{aligned}
y_{1 i}= & \beta_{0}+\beta_{1} \mathrm{TLR}+\beta_{2} \mathrm{TIE}+\beta_{3} \mathrm{GPMS}+\beta_{4} \mathrm{RD} \\
& +\beta_{5} \mathrm{LLR}+\beta_{6} \mathrm{FAR}+\beta_{7} \mathrm{CFR}+ \\
& \cdot \beta_{8} \mathrm{CR}+\beta_{9} \mathrm{QR}+\beta_{10} \mathrm{OR}+\beta_{11} \mathrm{EPS} \\
& +\beta_{12} \mathrm{DHB}+\beta_{13} \mathrm{CHB}+\varepsilon_{1 i} .
\end{aligned}
$$

Second stage: in the first stage, significant independent variables were introduced into the Heckman two-stage 
Table 2: Operational definition of each variable.

\begin{tabular}{|c|c|c|}
\hline Variable name & Narrative & Operational definition \\
\hline USER & Industry type & $\begin{array}{c}\text { Electronic appliances }=1 \\
\text { Plasticized textiles }=2 \\
\text { Construction of iron and steel }=3 \\
\text { Automobile transportation }=4 \\
\text { Comprehensive }=5 \\
\text { Financial }=6\end{array}$ \\
\hline DUC & $\begin{array}{c}\text { Use of derivative financial commodities } \\
\text { Derivative financial products }\end{array}$ & $\begin{array}{l}\text { Used }=1 ; \text { not } \text { used }=0 \\
\text { Forward forex }=1 \\
\text { Exchange contract }=2 \\
\text { Options }=3 \\
\text { Futures }=4\end{array}$ \\
\hline TLR & Debt ratio & Unit: \% \\
\hline LLR & Long-term debt ratio & Unit: \% \\
\hline CFR & Cash flow ratio & Unit: \% \\
\hline TIE & Interest coverage ratio & Unit: \% \\
\hline EPS & Earnings per share & Unit: yuan \\
\hline FAR & Fixed asset ratio & Unit: \% \\
\hline $\mathrm{DHB}$ & Shareholding ratio of directors and supervisors & Unit: \% \\
\hline $\mathrm{CHB}$ & Executive shareholding ratio & Unit: \% \\
\hline GPMS & Operating gross margin & Unit: \% \\
\hline $\mathrm{RD}$ & $\mathrm{R} \& \mathrm{D}$ expense ratio & Unit: \% \\
\hline OR & Operating income & Unit: yuan \\
\hline CR & Current ratio & Unit: \% \\
\hline $\mathrm{QR}$ & Quick ratio & Unit: \% \\
\hline
\end{tabular}

regression analysis, and the inverse Mills ratio was added to the equation model to control the problem of self-selective bias.

It is assumed that the distribution of the derivative hedging matrix is different from that with or without the operating derivative hedging matrix, and $Y_{1 i}^{*} Y_{2 i}^{*} Y_{3 i}^{*} Y_{4 i}^{*}$ is an unobservable random variable:

$$
\begin{aligned}
& Y_{i}^{*}=\beta_{i}^{\prime}+\varepsilon_{i}, \\
& Y_{1 i}^{*}=\beta_{1 i}^{\prime} X_{1 i}+\varepsilon_{1 i}, \\
& Y_{2 i}^{*}=\beta_{2 i}^{\prime} X_{2 i}+\varepsilon_{2 i}, \\
& Y_{3 i}^{*}=\beta_{3 i}^{\prime} X_{3 i}+\varepsilon_{3 i}, \\
& Y_{4 i}^{*}=\beta_{4 i}^{\prime} X_{4 i}+\varepsilon_{4 i} .
\end{aligned}
$$

Among them, $\varepsilon_{1 i} \sim\left(N, \sigma_{1}^{2}\right), \varepsilon_{2 i} \sim\left(N, \sigma_{2}^{2}\right), \varepsilon_{3 i} \sim\left(N, \sigma_{3}^{2}\right)$, $\varepsilon_{4 i} \sim\left(N, \sigma_{4}^{2}\right), X_{1 i}, X_{2 i}, X_{3 i}$, and $X_{4 i}$ are standard normal distribution. There are two types of explanatory variables in the two-stage model, (15) forward contract model, (16) exchange contract model, (17) option model, and (18) futures model. They are all unobservable variables, which are generally called latent variables. However, the $Y_{1 i}, Y_{2 i}, Y_{3 i}$, and $Y_{4 i}$ observed dummy variables can be used as the $Y_{1 i}^{*}, Y_{2 i}^{*}, Y_{3 i}^{*}$, and $Y_{4 i}^{*}$ substitute variables. For example, when $Y_{i}^{*}$ is greater than a certain threshold value $k$, it means that the enterprise has an operational hedging strategy; when $Y_{1 i}^{*}, Y_{2 i}^{*}, Y_{3 i}^{*}$, and $Y_{4 i}^{*}$ are greater than 0 , it means that the enterprise is operating on different derivative financial products:

$$
\begin{gathered}
Y_{i}= \begin{cases}1 & \text { if } Y_{i}^{*}>k, \\
0 & \text { if } Y_{i}^{*} \leq k,\end{cases} \\
Y_{1 i}= \begin{cases}1 & \text { if } Y_{1 i}^{*}>0, \\
0 & \text { if } Y_{1 i}^{*} \leq 0,\end{cases} \\
Y_{2 i}= \begin{cases}1 & \text { if } Y_{2 i}^{*}>0, \\
0 & \text { if } Y_{2 i}^{*} \leq 0,\end{cases} \\
Y_{3 i}= \begin{cases}1 & \text { if } Y_{3 i}^{*}>0, \\
0 & \text { if } Y_{3 i}^{*} \leq 0,\end{cases} \\
Y_{4 i}= \begin{cases}1 & \text { if } Y_{4 i}^{*}>0, \\
0 & \text { if } Y_{4 i}^{*} \leq 0,\end{cases}
\end{gathered}
$$

However, only when $Y_{i}=1, Y_{1 i}, Y_{2 i}, Y_{3 i}$ and $Y_{4 i}$ situations can be observed; in other words, only when the enterprise carries out derivatives operation, it will know the future derivatives target situation.

In this study, the two-stage procedure proposed by Heckman [13] was used to perform logistic regression analysis of model 1 and OLS regression of model 2 in order and to calculate the inverse Mills ratio. The two-stage procedure estimates the possible problem of self-selection by using the inverse Mills ratio. Sample selection bias is a limited dependent variable in econometrics, one of the research focuses of the variable model, meaning that the samples obtained cannot fully represent the matrix that the researchers are concerned about. Because the data type of this study is a nonrandom sample, in order to avoid this selfselection bias [13], we should add a control variable "inverse 
Mills ratio" to the model because "inverse Mills ratio" can reduce the occurrence of this phenomenon. The inverse scale of Mills can be derived from the probit model of selective function.

Firstly, probit regression model is used to estimate the coefficient of default behavior of the model, and the inverse Mills ratio is calculated, and then the ratio is added to the model as the control variable to correct the self-selectivity bias. Heckman proposed a two-stage modification method, also known as type II tobit model. First, the probit model was estimated in the first stage, and the inverse ratio of Mills was calculated. Then, the ratio was taken as an additional self-variable and incorporated into the OLS model for control and estimation. Sample selection bias in econometrics is one of the research fields of the limited dependent variable model. It means that the collected samples cannot fully represent the matrix of the research. If only the traditional least square method (OLS) is used to estimate the model parameters, the problem of sample bias will occur.

\section{Empirical Analysis}

In this research model, the extracted variables are substituted into the model, and the corresponding variables are the impact of the occurrence of operational risk aversion derivative financial product events. First, a statistical analysis is carried out from the perspective of the industry to illustrate the basic characteristics of the sample data in this research. The following are introduced, respectively.

4.1. Industry Analysis. The industry types of the samples in this study are classified variables, which are classified as 1, including electronic industry, electrical machinery industry, and electrical cable industry; 2 represents the plastic textile industry including plastic industry, textile industry, chemical industry, rubber industry, glass industry, paper industry, and biotechnology industry; 3 represents the construction of the steel industry, including construction industry, cement industry, and steel industry; 4 represents automobile transportation, including automobile industry, transportation industry, tourism industry, and shipping industry; 5 represents comprehensive category, including food industry, trade department store industry, and comprehensive enterprise category; and 6 represents the detailed distribution of banking, insurance, financial control, and securities, as shown in Table 3.

In the sample data of the research on the risk aversion derivative financial product events of enterprises, there are 296 electronic and electrical companies, accounting for $46.90 \%$ of the total sample companies. There are 130 plastic textile companies, accounting for $20.60 \%$ of the total sample, 69 steel companies, accounting for 10.93\%, 30 automobile transportation companies, accounting for 4.75\%, 69 comprehensive companies, accounting for $10.93 \%$, and $37 \mathrm{fi}-$ nancial companies, accounting for $5.86 \%$ of all sample companies, with a total of 631 listed companies.
4.2. Types of Derivative Financial Commodities. In this study, we will take the sample of the number of types of derivative financial products that enterprises operate to avoid risks. The typical examples are forward foreign exchange, exchange contracts, options, and futures. The distribution is shown in Table 4.

Among 631 listed companies in Taiwan, $48 \%$ to $57 \%$ use forward foreign exchange hedging, $22 \%$ to $32 \%$ operate exchange contract hedging, $13 \%$ to $17 \%$ use option contract hedging, and $5 \%$ to $7 \%$ use futures contract hedging.

Table 5 shows that, among the types of industries using forward contracts, $63 \%$ to $69 \%$ are in the electronic and electrical category, $17 \%$ to $21 \%$ in the plastic textile category, $2 \%$ to $6 \%$ in the steel construction category, $1 \%$ to $2 \%$ in the automobile transportation category, $4 \%$ to $9 \%$ in the comprehensive category, and $1 \%$ to $4 \%$ in the financial category.

The distribution is shown in Table 6. It can be seen that, among the 631 listed companies in Taiwan, the industry types of the hedgers in the operation exchange contracts of enterprises are the largest in the category of electronic appliances, the second in the category of finance, and the smallest in the category of automobile transportation.

The distribution is shown in Table 7 . The industry type of enterprises using option contracts to avoid risks is the largest in electronic appliances, the second in finance, and the smallest in automobile transportation.

The distribution is shown in Table 8. The industry type of enterprises using futures contracts to avoid risks is electronic appliances, followed by finance.

\subsection{Comparison of Characteristics of Hedging Companies} Using Derivative Financial Commodities. According to Table 9 in the bivariate regression model of the risk aversion events of the business operation derivative financial products, the impact of the variables included on the risk aversion events of the business operation derivative financial products is summarized as follows.

In the first stage, the third column of Table 9 is the variable estimation coefficient of this regression. The positive and negative signs of the coefficient can represent the procedure of whether to operate the risk avoidance. If the variable estimation coefficient is consistent with the previous expected signs, it means that these variables are suitable for this model, and it can be used to explain the relationship between the variable and the risk avoidance.

In addition, the correlation between the first-stage operational hedging model and the second-stage hedging category can be determined by the value of Mills lambda. The test statistic of the Mills lambda value reaches $5 \%$ statistical significance level, which means there is a significant correlation between the two-stage models; that is to say, there is a sample selection bias, which means that if we do not adopt the sample selection model, but adopt the traditional model to estimate, there will be a big bias. This empirical result shows that there is a significant correlation between the operation of risk aversion and the type of risk 
TABle 3: Number of industrial types.

\begin{tabular}{lccc}
\hline Data characteristics & Data category & Number of homes & Percentage (\%) \\
\hline & Electronic appliances & 296 & 46.90 \\
& Plasticized textiles & 130 & 20.60 \\
Industry & Construction of iron and steel & 69 & 10.93 \\
& Automobile transportation & 30 & 4.75 \\
& Comprehensive & 69 & 10.93 \\
& Financial & 37 & 5.86 \\
& Total & 631 & 100 \\
\hline
\end{tabular}

TABLE 4: Number of times of using derivative financial commodity types.

\begin{tabular}{lccccccc}
\hline & \multicolumn{2}{c}{ Forward forex } & \multicolumn{2}{c}{ Exchange contract } & \multicolumn{2}{c}{ Option } & \multicolumn{2}{c}{ Futures } \\
Date & Useful & $\%$ & Useful & $\%$ & Useful & \% & Useful \\
\hline $2015 / 3 / 01$ & 161 & 48.06 & 105 & 31.34 & 49 & 14.63 & 20 \\
$2015 / 6 / 1$ & 194 & 53.15 & 102 & 27.95 & 49 & 13.42 & 20 \\
$2015 / 9 / 1$ & 194 & 52.29 & 107 & 28.84 & 48 & 12.94 & 22 \\
$2015 / 12 / 1$ & 196 & 54.14 & 93 & 25.69 & 52 & 14.36 & 21 \\
$2016 / 3 / 1$ & 192 & 53.48 & 97 & 27.02 & 49 & 13.65 & 21 \\
$2016 / 6 / 1$ & 188 & 53.71 & 89 & 25.43 & 52 & 5.93 & 14.86 \\
$2016 / 9 / 1$ & 193 & 54.21 & 92 & 25.84 & 50 & 14.04 & 21 \\
$2016 / 12 / 1$ & 187 & 53.74 & 86 & 24.71 & 52 & 14.94 & 21 \\
$2017 / 3 / 1$ & 182 & 54.17 & 81 & 24.11 & 51 & 15.18 & 23 \\
$2017 / 6 / 1$ & 183 & 54.63 & 77 & 22.99 & 54 & 16.12 & 22 \\
$2017 / 9 / 1$ & 192 & 56.14 & 76 & 22.22 & 53 & 15.50 & 21 \\
\hline
\end{tabular}

aversion. Then, we will discuss the meaning behind the chosen explanatory variables in the first and second stages.

From the significant variables of the first-stage logistic regression model, the meaning of hedging is as follows.

4.3.1. Expected Financial Crisis Costs. The empirical results show that the lower the debt ratio is, the more likely it is to hedge. Because the enterprise may issue more convertible corporate bonds and the creditors of convertible corporate bonds have the right to convert the bonds into shares, when the creditors of convertible corporate bonds perform the conversion, the company's equity will increase, and the liabilities will decrease, so the lower the debt ratio of the company, the better the result of hedging. This result is the same as that of Tseng [16] and $\mathrm{Lu}$ [17]. It is also found that the higher the cash flow ratio is, the less the company will undertake derivative transactions of financial products, which is inconsistent with the research results of Guo [18], $\mathrm{Lu}$ [17], and Huang [8]. This proof is enough to show that the cash flow capital of the enterprise is too much to meet the current liabilities of the company, without relying on the operation of derivative financial products to maintain. The results show that the larger the long-term debt ratio is, the higher the willingness of enterprises to operate risk aversion is, which may reduce the unstable risk of purchasing longterm debt expenditure for enterprises willing to operate risk aversion, transfer the company's liabilities, and improve the degree of capitalization.

4.3.2. Tax Benefits. It is found that the interest cover ratio is a positive change, that is, the higher the interest cover ratio is, the higher the willingness of the enterprise to engage in hedging operations is. The higher the ratio is, the higher the creditor's degree of protection is, that is, the higher the debtor's ability to pay interest after operating derivative financial products is. However, the $p$ value shows that the interest cover ratio is not significant, which may have been biased in the past literature.

4.3.3. Enterprise Scale. The empirical results show that the higher the ratio of fixed assets and earnings per share, the more likely to hedge. This evidence shows that when the profitability is higher, enterprises with larger fixed assets will be more willing and able to recruit managers with professional knowledge of risk management to engage in relevant hedging actions. The results are the same as those of $\mathrm{Hsu}$ [19], Guo [18], Chen [20], Tseng [16], and Lu [17] which also support that the larger the company is, the more it will undertake derivative financial products.

4.3.4. Equity Agency Issues. The problem of agency caused by the separation of management rights and ownership of enterprises is to measure the agency cost between managers and shareholders based on the shareholding ratio of directors and supervisors and the shareholding ratio of managers. According to the research of Huang [8], the higher the shareholding ratio of directors and supervisors, the chairman or the general manager is an important decision maker in risk management and the choice of hedging tools and objects, which can determine the direction of enterprise decision-making, without the need to reduce risk by operating hedging. It is found that the higher the shareholding ratio is, the more risk averse the managers will be. The reason may be that although the hedging policies of 


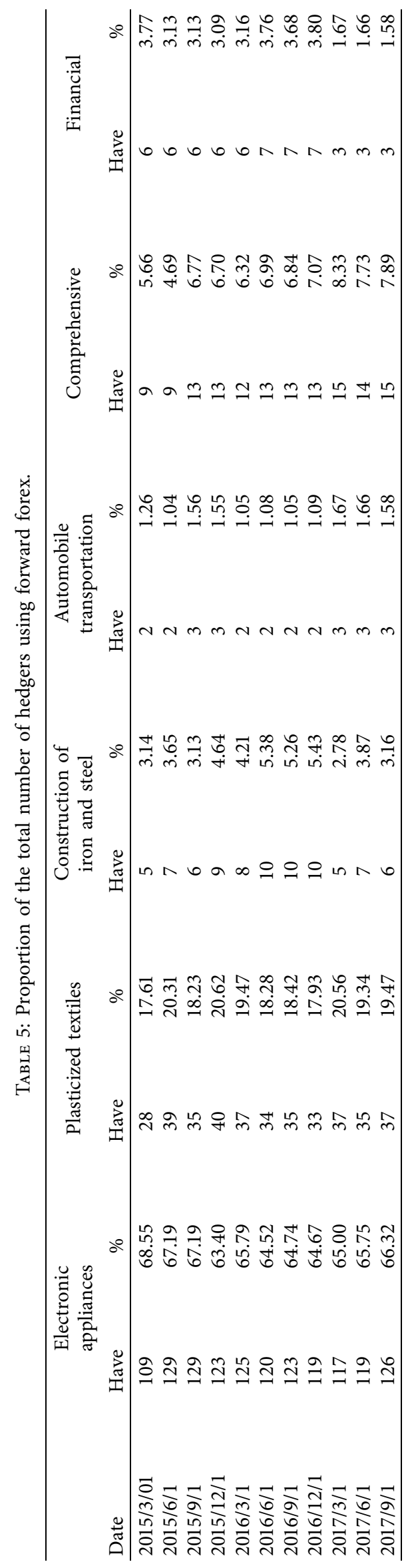




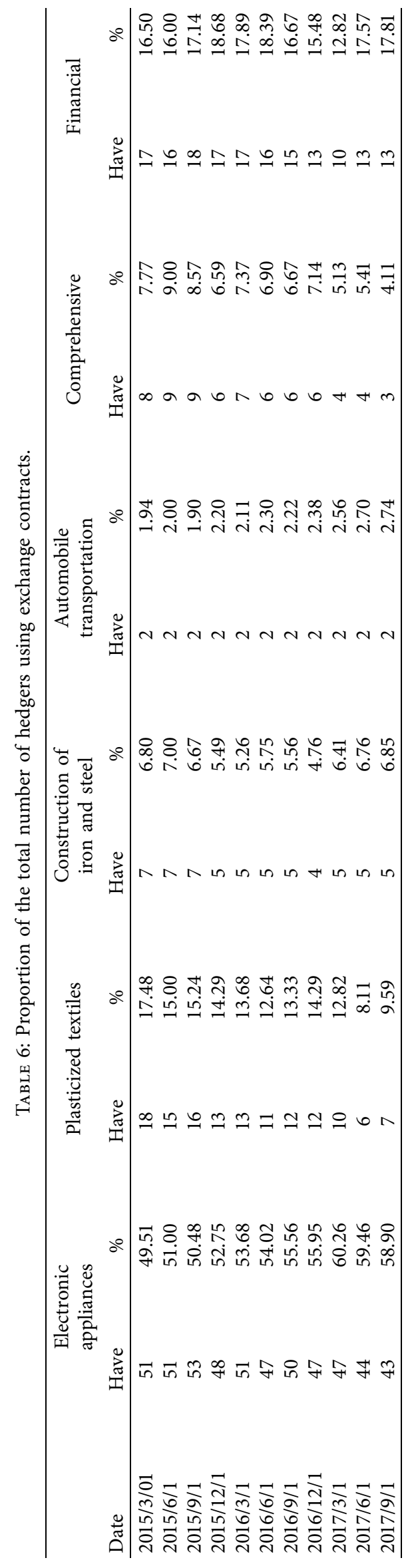












TABLE 9: Logistic model estimation table.

\begin{tabular}{|c|c|c|c|c|c|}
\hline With or without hedging & Variable & Estimated coefficient & Standard error & $Z$ value & $p$ value \\
\hline & Debt ratio (TLR) & -0.0099932 & 0.0012326 & -8.11 & $p \leq 0.001$ \\
\hline & Interest coverage (TIE) & $5.10 e-07$ & $6.69 e-07$ & 0.76 & 0.447 \\
\hline & Operating gross margin (GPMS) & -0.0062112 & 0.0010302 & -6.03 & $p \leq 0.001$ \\
\hline & Research and development cost ratio (RD) & -0.0004225 & 0.0007332 & -0.58 & 0.564 \\
\hline & Long-term debt ratio (LLR) & 1.626623 & 0.1936501 & 8.40 & $p \leq 0.001$ \\
\hline & Fixed asset ratio (FAR) & -0.7484093 & 0.091008 & -8.22 & $p \leq 0.001$ \\
\hline & Cash flow ratio (CFR) & -0.0009186 & 0.0003446 & -2.67 & 0.008 \\
\hline & Current ratio (CR) & -0.0038123 & 0.0003031 & -12.58 & $p \leq 0.001$ \\
\hline & Quick ratio (QR) & 0.0038373 & 0.0003218 & 11.92 & $p \leq 0.001$ \\
\hline & Operating income (OR) & $4.18 e-09$ & $5.58 e-10$ & 7.50 & $p \leq 0.001$ \\
\hline & Earnings per share (EPS) & 0.0881332 & 0.0093118 & 9.46 & $p \leq 0.001$ \\
\hline & Director and supervisor shareholding ratio (DHB) & -0.0077495 & 0.0010447 & -7.42 & $p \leq 0.001$ \\
\hline & Executive shareholding ratio $(\mathrm{CHB})$ & 0.0156009 & 0.0070627 & 2.21 & 0.027 \\
\hline & _cons & 0.7147989 & 0.0637489 & 11.21 & $p \leq 0.001$ \\
\hline \multirow{4}{*}{ Mills } & Lambda & -0.1925676 & 0.2226741 & -0.86 & 0.038 \\
\hline & Rho & -0.21383 & & & \\
\hline & Sigma & 0.9005568 & & & \\
\hline & Lambda & -0.1925676 & 0.2226741 & & \\
\hline
\end{tabular}

Chinese enterprises are mostly decided by the board of directors, the financial directors and financial departments are responsible for the actual implementation of hedging transactions in terms of the selection of hedging tools and objects. Lu [17] and Cheng [21] found that the test results were the same as the expected direction.

4.3.5. Growth Investment Opportunities. The higher the operating income is, the more the derivative financial products will be undertaken. The company has surplus capital to conduct hedging operations to ensure that the company's value is lost due to the risk of market fluctuation. The higher the gross profit margin is, the lower the risk aversion intention of the enterprise is. The profit earned by the net operating income of the enterprise is only listed as income and improves the book performance, without considering the risk aversion behavior.

4.3.6. Information Asymmetry. The higher the current ratio is, the lower the willingness to operate risk aversion is, which shows that when the capital is sufficient to meet the current cost loss, the enterprise will not consider operational risk aversion. The results also show that the smaller the quick ratio is, the higher the risk aversion is. Due to the possible increase of inventory and prepayment cost, the quick assets of the enterprise decrease, and they are unwilling to use excess funds for hedging.

From the results of Heckman's two-stage regression analysis, the meaning of its hedging strategy is simply explained as follows.

The empirical results after adding the virtual variable of the hedging type in model 2 found that the expected direction of each variable was roughly the same as the result of the virtual variable without the hedging type (model 1). According to the analysis results, the regression results of the second stage of risk hedging model (consider the effects of operating derivative financial products and the company's self-selection of the hedging category). Table 10 shows the regression results of the second-stage hedging category model. Model 1 is added to the risk-averse category model to examine the possible impact of self-selection bias. Because the listed companies undertake the hedging of derivative financial products, the determinants of hedging may be different, so the six levels of the sample area are analyzed. The results in Table 9 show that the gross profit margin (GPMS), long-term debt ratio (LLR), and manager's shareholding ratio (CHB) are significantly positively correlated, indicating that the higher the cost of financial crisis, the more equity agency problems. The greater the opportunity for growth investment, the higher the degree of choice for hedging. The debt ratio can be used as an important index to measure the financial risk of a company. The research results show that the debt ratio and the type of risk avoidance are significantly negatively correlated in the cost of financial crisis. As Gul and Tsui [22] pointed out, the debt executor's appointment restricts the manager to engage in activities that violate the company's interests, thus reducing the company's financial crisis cost. Therefore, the type of risk avoidance can be selected as follows.

However, the first mock exam and the gross profit margin of business show a contrary result in the previous model. It shows that the bias in the past literature has been made when choosing samples again. It is known from the empirical results that when the gross profit margin is higher, the risk of avoiding risk will be increased, and the $p$ value will be significant. The higher the operating income is, the lower the hedging effect of the enterprise is, which shows that an enterprise causes losses in the choice of hedging types and also highlights that there is a big error in growth investment opportunities in the past financial reports.

The results show that there is a significant correlation between the two-stage model of hedging operation and the type of hedging. That is to say, only considering the model 
TABle 10: Parameter estimation table of the Heckman sample selection model.

\begin{tabular}{|c|c|c|c|c|c|}
\hline $\begin{array}{l}\text { Number of obs }=7 \\
\text { Censored obs }=392 \\
\text { Uncensored obs }=3 \\
\text { Wald } \operatorname{chi}^{2}(10)=11 \text { c } \\
\text { Prob }>\operatorname{chi}^{2}=0.0000\end{array}$ & $\begin{array}{l}7 \\
484 \\
62\end{array}$ & & & & \\
\hline & Variable & Estimated coefficient & Standard error & $Z$ value & $p$ value \\
\hline & Debt ratio (TLR) & -0.0098526 & 0.0019086 & -5.16 & $p \leq 0.001$ \\
\hline & Operating gross margin (GPMS) & 0.0030374 & 0.0014012 & 2.17 & 0.030 \\
\hline & Long-term debt ratio (LLR) & 1.381609 & 0.3062144 & 4.51 & $p \leq 0.001$ \\
\hline & Fixed asset ratio (FAR) & -0.5702037 & 0.1452769 & -3.92 & $p \leq 0.001$ \\
\hline & Cash flow ratio (CFR) & 0.000092 & 0.000429 & 0.21 & 0.830 \\
\hline Hedging category & Current ratio (CR) & -0.0014274 & 0.0006959 & -2.05 & 0.040 \\
\hline & Quick ratio (QR) & 0.0010574 & 0.0007212 & 1.47 & 0.143 \\
\hline & Operating income (OR) & $-5.53 e-10$ & $3.06 e-10$ & -1.81 & 0.071 \\
\hline & Earnings per share (EPS) & -0.01139 & 0.0106861 & -1.07 & 0.286 \\
\hline & Director and supervisor shareholding ratio (DHB) & -0.0033535 & 0.0015209 & 2.20 & 0.027 \\
\hline & Executive shareholding ratio $(\mathrm{CHB})$ & 0.0483558 & 0.0083939 & 5.76 & $p \leq 0.001$ \\
\hline & _cons & 2.180772 & 0.1070058 & 20.38 & $p \leq 0.001$ \\
\hline
\end{tabular}

established by the sample of hedging operation, there is a problem of sample selection bias. Therefore, in the future, when establishing the model of hedging operation, it is advisable to consider the problem of sample selection bias and establish the model of hedging operation with the twostage regression model, so as to avoid the problem of sample selection bias due to the difference between the hedging operation and the sample allocation of the type of hedging and improve the prediction ability of the model. This paper uses the two-stage sample selection model proposed by Heckman [13] to make relevant corrections, and the results of the study also show that the revised Heckman [13] twostage sample selection model indeed can correct the sample selection error of traditional models and improve the stability of the models; then, we can continue the relevant research or compare the correction methods of the sample selection errors mentioned above and further analyze them.

\section{Conclusions and Recommendations}

5.1. Research Conclusions. The main purpose of this study is to analyze the relationship between the hedging of derivative financial products and the characteristics of enterprises and the factors that affect the hedging decision-making based on the situation of Taiwan listed companies undertaking derivative financial products from 2015 to 2017. At the same time, it discusses the key factors that affect the degree of risk avoidance. Through the discussion and analysis of the above chapters, the following conclusions are concluded.

\subsubsection{Hedging of Derivative Financial Products by Listed} Companies in Taiwan. Among 631 listed companies in Taiwan, $27 \%$ to $52 \%$ use forward contracts, $11 \%$ to $17 \%$ use exchange contracts, $6 \%$ to $9 \%$ use option contracts, and $2 \%$ to $4 \%$ use futures contracts to hedge. This result shows that no matter what kind of listed companies, forward contracts are the most frequently used as hedging tools, while exchange contracts and option contracts are the second, and companies using futures contracts are very few.

5.1.2. Factors Influencing the Company's Operation of Derivative Financial Products for Hedging. After using logistic regression in the first stage, its Taiwan listed companies operated derivative financial commodity hedging behaviors. There were 13 variables: debt ratio, interest protection multiple, operating margin, research and development expense ratio, long-term debt ratio, fixed asset ratio, cash flow ratio, current ratio, quick ratio, operating income, earnings per share, director and supervisor's shareholding ratio, and manager's shareholding ratio. In a company's derivative financial products' hedging regression model, smaller debt ratio and longer-term debt ratio enterprises with large and small cash flow ratios are more likely to operate derivative financial commodity hedging behaviors; here, the debt ratio, long-term debt ratio, and cash flow ratio representing the expected financial crisis costs are in line with this result. The larger the earnings per share is, the larger the fixed asset ratio is and the more the enterprises will operate derivative financial product hedging behavior; in this case, it represents the earnings per share of the enterprise scale, and the fixed asset ratio conforms to this result. The smaller the shareholding ratio of directors and supervisors is, larger shareholding ratio of managers will tend to use derivative financial products; in this case, the shareholding ratio of directors and supervisors, which represents equity issues, meets this result. The smaller the operating gross profit rate is, the smaller the operating income is and the more likely the enterprise will operate the hedging behavior of derivative financial products; here, it represents the operating gross profit rate of growth investment opportunities, and the operating income conforms to this result. The smaller the current ratio is, the larger the quick ratio is and the more likely the enterprises are to use derivative financial products; this represents the current ratio with asymmetric information, and the quick ratio conforms to this result. 
Among them, the interest cover ratio and research and development expense ratio are not significantly inconsistent with the expectation, which indicates that there is a bias problem in the financial data. It is necessary to adjust the bias of sample selection through lambda. According to Heckman's [13] two-stage estimation theory, to correct the bias of sample selection, the two-stage estimation of self-selection and Heckman $[13,23]$ will make the extracted samples have distinctive differences. In order to stabilize the data, we first need to find out the correction item (inverse Mills ratio) to replace the possible factors that affect the operation avoidance. In the second stage, the third coefficient in $\mathrm{Ta}-$ ble 10 is also the regression variable estimation coefficient. The positive and negative signs of the coefficient can represent the relationship between the coefficient and the type of risk avoidance. The sign of the coefficient of variable estimation is compared with the expected sign of the variable. If the coefficient of variable estimation is identical with the previous expected sign, it represents that these variables are suitable for this model, and the relationship between the coefficient of the variable and the type of risk avoidance can be explained.

After using Heckman's two-stage regression estimation, there were 11 variables: debt ratio, operating gross margin, long-term debt ratio, fixed asset ratio, cash flow ratio, current ratio, quick ratio, operating income, earnings per share, director and supervisor's shareholding ratio, and manager's shareholding ratio. In the regression model of choosing the type of risk aversion for enterprises to operate derivative financial products, enterprises with smaller debt ratio and larger long-term debt ratio will operate derivative financial products to avoid risks; the debt ratio and longterm debt ratio representing the expected financial crisis cost meet this result. The smaller the ratio of fixed assets is, the more likely the enterprise will operate the hedging behavior of derivative financial products; the ratio of fixed assets representing the enterprise scale here conforms to this result. The smaller the shareholding ratio of directors and supervisors is, the greater the shareholding ratio of managers will tend to use derivative financial products; in this case, the shareholding ratio of directors and supervisors, which represents equity issues, meets this result. The larger the operating gross profit rate is, the smaller the operating income is and the more likely the enterprise will operate the hedging behavior of derivative financial products; here, it represents the operating gross profit rate of growth investment opportunities, and the operating income conforms to this result. The smaller the current ratio is, the more likely the firm is to use derivative financial products; the current ratio representing information asymmetry is in line with this result.

The factors that affect the use of derivative financial products include company size, financial crisis cost, tax benefits, enterprise size, equity issues, growth investment opportunities, and information asymmetry. To sum up, companies with larger long-term debt ratio, more tax-saving projects, larger enterprise scale, more opportunities for growth investment, and higher degree of information asymmetry will tend to use derivative financial products to avoid risks. There are financial crisis cost, growth investment opportunity, company size, and other factors that will affect the company's decision to use forward contract hedging. Among them, smaller debt ratio of financial crisis cost and the higher long-term debt ratio, enterprises tend to avoid risks. And the higher the gross profit margin and the lower the income, the higher the risk aversion.

In terms of using exchange contracts to avoid risks, there are factors such as the cost of equity agency, the cost of financial crisis, growth investment opportunities, and the size of the company, which will affect the company's decision to use hedging. Among them, the smaller the manager's shareholding ratio, the higher the long-term debt ratio of financial crisis cost, the higher the growth investment opportunity, the larger the company scale, and the higher the degree of information asymmetry, the higher the degree of risk avoidance. There are financial crisis cost, growth investment opportunity, and company size that will affect the company's hedging decision. The higher the long-term debt ratio in the cost of financial crisis, the higher the growth investment opportunities, and the larger the company scale, the higher the degree of risk avoidance. To sum up, the larger the long-term debt ratio in the cost of financial crisis, the greater the pressure of long-term debt repayment. On the contrary, the smaller the long-term debt ratio, the less the pressure of long-term debt repayment.

\subsection{Research Recommendations}

5.2.1. Suggestions for the Industry. For the transaction of derivative financial products, the internal control of the enterprise must be strictly implemented, and the operation of derivative financial products should be included in the company's operational procedures, such as clearly limiting the types of derivative financial products that can be traded, the upper limit of transaction amount, and the audit responsibilities of the responsible units. However, after the announcement of Taiwan's bulletin No. 34 and No. 36, this study also found that in fact, the disclosure of derivative financial product investment information by Taiwan's listed companies still needs to be improved; at least, the disclosure of the reasons for engaging in this behavior is still insufficient; that is to say, the disclosure of only the amount of use needs to be improved. In any case, the empirical findings of this study show that the risk aversion activities of enterprises are related to corporate characteristics, such as agency cost, corporate scale, financial crisis cost, and growth investment opportunities. Enterprises can use these characteristics to evaluate themselves as a reference for risk aversion decisionmaking. Secondly, the hedging effect can be fully achieved only when the hedging tools of different natures are used in the appropriate risk types. Enterprises should know their own financial characteristics and have all kinds of knowledge of derivative financial products, so as to find more suitable hedging tools for enterprises and maximize the hedging benefits. Some suggestions are put forward:

(1) Risk management should be a basic routine financial operation for enterprises. Because most of the 
foreign exchange risks faced by enterprises cannot be accurately predicted in advance, the risk avoidance of foreign exchange should be a long-term expenditure, and the company's foreign exchange position should be controlled for a long time.

(2) At present, Taiwan's enterprises do not have enough knowledge of derivative financial products and professional talents. Therefore, how to actively cultivate risk management talents and strengthen the training of risk management knowledge is an important task for enterprises facing the unpredictable international financial environment.

(3) Different hedging tools have different product attributes. When a company chooses suitable hedging tools, the risk characteristics of the managed assets must be as close as possible to the hedging tools.

5.2.2. Industrial Factors and the Impact of the Implementation of Taiwan Bulletin No. 34 and No. 36. After the implementation of bulletin No. 34 and bulletin No. 36, the significance of the three variables, interest cover ratio, shareholding ratio of directors and supervisors, and research and development expense ratio, is significantly lower, and the change is not significant. The results show that the overall variables are not significant, which shows that Taiwan's implementation of bulletin No. 34 and No. 36 has a certain impact on the undertaking of derivative financial products.

\subsubsection{Suggestions for Enterprises and Related Institutions.}

(1)

With the rapid development of derivative financial products, there are many kinds of products that can be used by enterprises. If enterprises want to avoid risks, they should choose derivative financial products in a simple form or use natural methods to avoid risks. Because of the complexity of structural products, it is not easy to evaluate them, and it is not easy to operate them to achieve the original purpose of avoiding risks.

(2) When an enterprise uses derivative financial products, if its main purpose is to avoid risks, it should not only be limited to exchange rate or interest rate risks but also the hedging activities of other risks which are very important. Risk aversion is one of the key factors for enterprises to make profits. Enterprises should use derivative financial products carefully and effectively to avoid risks.

(3) At present, although the expression and disclosure of derivative financial products have been implemented through bulletin No. 34 and bulletin No. 36, there are relatively complete specifications, but how to evaluate the fair value of derivative financial products correctly and objectively is still a big problem. Relevant institutions should establish a complete evaluation mechanism to standardize the evaluation.

\section{Data Availability}

The data used to support the findings of this study are available from the corresponding author upon request.

\section{Conflicts of Interest}

The authors declare that they have no conflicts of interest.

\section{References}

[1] P. S. Ko, C. C. Wu, M. J. Cheng, and Y. S. Chen, "Evaluation on the hedge operation of derivative financial products of non-financial insurance listed companies in Taiwan," Taiwan Financial Quarterly, vol. 11, no. 1, pp. 1-31, 2010.

[2] D. Mayers and C. W. Smith, "On the corporate demand for insurance," The Journal of Business, vol. 55, no. 2, pp. 281-296, 1982.

[3] C. W. Smith and R. M. Stulz, "The determinants of firms' hedging policies," The Journal of Financial and Quantitative Analysis, vol. 20, no. 4, pp. 391-405, 1985.

[4] C. Géczy, B. A. Minton, and C. Schrand, "Why firms use currency derivatives," The Journal of Finance, vol. 52, no. 4, pp. 1323-1354, 1997.

[5] S. L. Mian, "Evidence on corporate hedging policy," The Journal of Financial and Quantitative Analysis, vol. 31, no. 3, pp. 419-439, 1996.

[6] N. L. Joseph, "The choice of hedging techniques and the characteristics of UK industrial firm," Journal of Multinational Financial Management, vol. 10, no. 2, pp. 164-184, 2000.

[7] H. Nguyen and R. Faff, "On the determinants of derivative usage by Australian companies," Australian Journal of Management, vol. 27, no. 1, pp. 1-24, 2002.

[8] Y. P. Huang, A Study on the Motivation and Behavior of Listed Companies' Use of Derivative Financial Products for Hedging, Cheng Kung University, Tainan, Taiwan, 2000.

[9] Y. C. Kuo, Impacts of Corporate Characteristics and Financial Robustness on Derivative Transactions for Listed Companies of Taiwan, Taipei University, New Taipei City, Taiwan, 2009.

[10] L. C. Tsai, "Analysis of influencing factors on the use of derivative financial instruments by enterprises-taking the electronics industry in Taiwan as an example," Finance and Accounting News, vol. 8, pp. 99-105, 2015.

[11] P. Tufano, "Who manages risk? an empirical examination of risk management practices in the gold mining industry," The Journal of Finance, vol. 51, no. 4, pp. 1097-1137, 1996.

[12] G. D. Haushalter, "Financing policy, basis risk, and corporate hedging: evidence from oil and gas producers," The Journal of Finance, vol. 55, no. 1, pp. 107-152, 2000.

[13] J. J. Heckman, "Sample selection bias as a specification error," Econometrica, vol. 47, no. 1, pp. 153-161, 1979.

[14] M. J. Shiue, Y. S. Chang, and C. T. Kao, "The company selfselects the appointment of accountants and auditing fees," Contemporary Accounting, vol. 9, no. 2, pp. 167-200, 2008.

[15] Y. L. Lin, T. C. Chang, and S. B. Huang, "Study on sample selection errors in enterprise financial crisis early warning model: a case study of listed companies in taiwan," Economic Research, vol. 46, no. 2, pp. 285-319, 2010.

[16] M. Y. Tseng, An Empirical Study on the Relationship between Hedging by Derivatives and Corporate Characteristics for Listed Companies in Taiwan, Dong Hwa University, Hualien, Taiwan, 2004. 
[17] W. J. Lu, The Use of Derivatives in the Taiwan Electronic Industry, Taiwan University, Taipei, Taiwan, 2001.

[18] Y. J. Guo, The Impact of Corporate Characteristics and Financial Soundness of Listed Companies in Taiwan on the Operation of Derivative Financial Products, Taipei University, Taipei, Taiwan, 2009.

[19] J. C. Hsu, A Study on Derivatives Trading and Corporate Characteristics for Taiwanese Electronics Industry, Jinan University, Guangzhou, China, 2010.

[20] M. H. Chen, A Study on Derivatives Trading and Corporate Characteristics for Taiwanese Listed Companies, Yunlin University of Science and Technology, Douliu, Taiwan, 2007.

[21] Y. L. Cheng, A Study of the Use of Derivatives for Hedging by Multinational Operation and International Finance Firms in Taiwanese Electronics Industry, Dong Hwa University, Hualien, Taiwan, 2005

[22] F. A. Gul and J. Tsui, "A test of the free cash flow and debt monitoring hypotheses: evidence from audit pricing," Journal of Accounting and Economics, vol. 24, no. 2, pp. 219-237, 1998.

[23] J. J. Heckman, "The common structure of statistical models of truncation, sample selection and limited dependent variables and a simple estimator for such models," The Annals of Economic and Social Measurement, vol. 5, no. 4, pp. 475-492, 1976. 